\title{
Differential effects of nasal continuous positive airway pressure on reversible or fixed upper and lower airway obstruction
}

\author{
C-H. Wang, H-C. Lin, T-J. Huang, C-T. Yang, C-T. Yu, H-P. Kuo
}

Differential effects of nasal continuous positive airway pressure on reversible or fixed upper and lower airway obstruction. C-H. Wang, H-C. Lin, T-J. Huang, C-T. Yang, C-

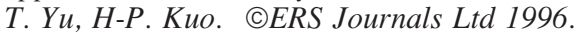

ABSTRACT: Our study was to assess whether there were differential effects of nasal continuous positive airway pressure (nCPAP) on different kinds of obstruction in either upper or lower airways in patients with chronic obstructive pulmonary disease (COPD).

nCPAP (6 $\mathrm{cmH}_{2} \mathrm{O}$ for ten minutes) was applied to 7 patients with reversible extrathoracic upper airway obstruction (RUAO) and 3 patients with fixed extrathoracic upper airway obstruction (FUAO). Eighteen stable asthmatics, receiving methacholine challenge to induce a more than $20 \%$ reduction in $\mathrm{FEV} 1$, were randomly investigated for the effect of nCPAP or sham pressure on reversible lower airway obstruction. Nine stable COPD patients were enrolled to study the effect on irreversible lower airway obstruction. Maximal expiratory and inspiratory flow volume curves and dyspnoea scores were obtained before and after immediate withdrawal of nCPAP.

In the RUAO group, nCPAP significantly improved stridor and dyspnoea scores, decreased the ratio of FEF50/FIF50 from $2.05 \pm 0.25$ to $1.42 \pm 0.16$, and increased peak inspiratory flow (PIF) as well as forced inspiratory vital capacity by $26 \pm 8 \%$ and $9 \pm 4 \%$, respectively. In expiratory phase, there was no significant change in pulmonary functions. In asthmatics, nCPAP significantly reversed methacholine-induced bronchoconstriction increasing forced vital capacity by $10 \pm 3 \%$, FEV1 by $15 \pm 4 \%$ and PIF by $32 \pm 11 \%$. nCPAP significantly increased the response to bronchodilators. The improvement in airflow rate persisted for at least 5 min after nCPAP withdrawal and was highly correlated with the response to bronchodilators. There was no significant effect of nCPAP on airflow rate in COPD patients. Subjective dyspnoea score changes paralleled the pulmonary function improvement.

We conclude that there are differential effects of nCPAP on airflow rates in patients with different nature of airway obstruction. Patients with airway obstruction caused by structural changes may not benefit from the use of nCPAP in improving airflow rates.

Eur Respir J. 1996, 9, 952-959.
Dept of Thoracic Medicine, Chang Gung Memorial Hospital, Taipei, Taiwan.

Correspondence: H-P. Kuo Dept of Thoracic Medicine Chang Gung Memorial Hospital 199 Tun-Hwa N. Rd

Taipei

Taiwan

Keywords: Airway obstruction nasal continuous positive airway pressure respiratory function tests

Received: September 151995

Accepted after revision December 261995
Nasal continuous positive airway pressure (nCPAP) is widely established in the treatment of obstructive sleep apnoea syndrome. nCPAP exerts a pneumatic splinting effect, which counteracts the closure of elastic upper airway in order to prevent airway collapse and to abolish snoring and clinical complications [1-4]. To hold the compromised airway open, nCPAP has also been used successfully in the treatment of transient vocal paralysis after tracheal tumour operation [5], instability of the airway in tracheomalacia [6], or as an effective treatment for apnoea in premature infants by decreasing supraglottic resistance $[7,8]$.

Recently, the application of external positive end-expiratory pressure (PEEP) in patients with assisted mechanical ventilation, or continuous positive airway pressure (CPAP) in spontaneously breathing patients, has been shown to reduce the work of breathing by overcoming auto-PEEP to minimize dynamic airway collapse during expiration in patients with airflow obstruction [9-11]. Although PEEP or CPAP might dilate collapsed or severely narrowed airways, the use of PEEP or nCPAP in obstructive lung diseases is controversial [10, 12-15]. During acute exacerbation of chronic obstructive pulmonary disease (COPD) with no response to conventional medical treatment, nCPAP was introduced as a noninvasive procedure to prevent intubation [10]. However, nCPAP was shown to have a negative effect on lung mechanics in infants with acute bronchiolitis [13]. PEEP-mask had no clinical benefit in stable COPD patients with hypersecretion of mucus [14]. In contrast, PEEP may improve exercise-induced bronchospasm [15]. For those patients with airway obstruction, the effect of an increase in endexpiratory pressure on airway resistance may be balanced between the "pneumatic splint", which overcomes airway obstruction, and the imposed pressure at endexpiratory ventilation, which causes airflow retardation. 
There is little information regarding the effect of continuous positive pressure on airway resistance in patients with obstructive airways. Bronchial asthma and COPD are two of the most common obstructive airway disorders. Airway inflammation is the underlying mechanism for bronchial asthma [16]. It is responsible for the development of hyperresponsiveness of airway smooth muscle leading to reversible airway obstruction. In contrast, structural changes in the airway walls and lung parenchyma are the principal mechanisms for irreversible airway obstruction in patients with COPD. In upper airway obstruction, reversible extrathoracic airway obstruction (RUAO), an increase in the velocity of air passing through the site of narrowing reduces intraluminal pressure to induce pharyngeal collapse at a given site of narrowing during inspiration. However, the change in the airflow rate does not significantly alter in fixed extrathoracic airway obstruction (FUAO) during either the inspiratory or expiratory phases.

It is not known whether the different mechanisms underlying airway obstruction may cause a difference in the effect of nCPAP on the airway resistance in RUAO and FUAO. Hence, we investigated the possible differential effect of nCPAP on airway resistance in patients with COPD and stable bronchial asthma after induction of reversible airway obstruction by methacholine. We also examined the possible differential effect of nCPAP on airflow rates in patients with RUAO and FUAO, which might be more sensitive to intraluminal pressure change.

\section{Materials and methods}

\section{Subjects}

Eighteen stable asthmatics, fulfilling the criteria of asthma according to the American Thoracic Society (ATS) definition [17] and free of symptoms with normal pulmonary function (aged 16-58 yrs; 8 females and 10 males), were referred to our pulmonary function laboratory for methacholine provocation test. Bronchoconstriction was induced by aerosolizing a solution of methacholine with five breaths from a Rosenthal Dosimeter. If the forced expiratory volume in one second (FEV1) was not reduced by more than $10 \%$ from baseline by buffered solution (phosphate-buffered saline (PBS), $\mathrm{pH} 7.4$ ), the patients were challenged with increasing concentrations of methacholine at $5 \mathrm{~min}$ intervals. Starting with $0.075 \mathrm{mg} \cdot \mathrm{mL}^{-1}$, the methacholine concentration was progressively doubled until the FEV1 was reduced by more than $20 \%$ from the baseline value. During the procedure of methacholine challenge, patients did not receive nCPAP or sham pressure.

Nine COPD patients (aged 64-73 yrs; 2 females and 7 males), who were clinically stable without acute exacerbation due to any cause or any evidence of airway infection within the previous 3 months, were enrolled in the study. All patients had a bronchodilator response of less than $10 \%$ from baseline in either lung volume or FEV1.

To examine the effect of nCPAP on extrathoracic upper airway obstruction, seven female subjects (32-61 yrs of age) with RUAO comprising six subjects with bilateral vocal cord paralysis after thyroidectomy and one with vocal cord oedema after extubation, and three patients ( 2 females and 1 male; aged 37-66 yrs) with FUAO comprising one patient with postoperative narrowed vocal cords following laryngeal tumour and two patients with tracheal stenosis of unknown cause, were enrolled in this study. Patients with RUAO presented with inspiratory stridor, loss of voice, hoarseness, dyspnoea on exercise, or loud snoring. The extrathoracic upper airway obstruction was documented by the flow-volume loops [18], and under direct laryngoscopy or flexible fibreoptic bronchoscopic examinations. The baseline data of the patients are listed in table 1. Patients with RUAO and FUAO had forced inspiratory flow (FIF) $\leq 100 \mathrm{~L} \cdot \mathrm{min}^{-1}$, FEV1/ peak expiratory flow $(\mathrm{PEF}) \geq 10 \mathrm{~mL} \cdot \mathrm{L}^{-1} \cdot \mathrm{min}$, and forced expiratory flow to inspiratory flow at $50 \%$ vital capacity $($ FEF50/FIF50) $\geq 1$, which were compatible with the criteria of upper airway obstruction [19].

\section{Apparatus of $n C P A P$ and sham pressure}

Patients were fitted with a suitable nasal mask, and CPAP was delivered from a flow generator (CPAP model 7100; Healthdyne, Marietta, GA, USA) that provided a continuous flow of room air throughout the respiratory cycle. The pressure was adjusted with the threshold valves. Patients with asthma wearing a nCPAP mask without application of positive pressure were considered as a control group (sham pressure group). The sham pressure circuit was set up similarly, except that no flow was generated.

\section{Determination of the level and duration of $n C P A P$}

To select an acceptable pressure and duration of nCPAP to be applied to each subject, different levels of pressure with variable duration were applied to all patients in a preliminary study 4 weeks earlier. A nCPAP level of 6 $\mathrm{cmH}_{2} \mathrm{O}$ for $10 \mathrm{~min}$ was chosen, since it was well tolerated by all patients. Higher pressure or longer duration of nCPAP was not tolerated by all patients with FUAO and some others due to an irritating sensation and dryness of the nasal mucosa. Some patients could not tolerate the flow and pressure of nCPAP when it was administered for the first time; therefore, to avoid the problem of acclimatization to nCPAP, each patient was familiarized with the flow and pressure of nCPAP for at least 1 or 2 weeks before the study.

\section{Study design}

Initially, flow-volume loops were recorded for all subjects by means of a pressure-differential body plethysmograph (Gould, System 2800; SensorMedics Corp.) with a heated pneumotachometer for measurement of flow. A minimum of three acceptable tests were ob-tained; both the forced expiratory vital capacity (FVC) and FEV1 values were within $5 \%$ or $100 \mathrm{~mL}$ according to the recommendations of the ATS [20]. The baseline parameters of FVC, FEV1, FEV1/FVC, PEF, forced expiratory 
flow at 25 and $75 \%$ vital capacity (FEF25-75\%), isovolume forced expiratory flow at 25 and $75 \%$ vital capacity (isoFEF25-75\%), peak inspiratory flow (PIF), forced inspiratory vital capacity (FIVC) and FEF50/FIF50 were recorded.

The effect of nCPAP on pulmonary function was measured immediately after abrupt cessation of nCPAP. nCPAP $\left(6 \mathrm{cmH}_{2} \mathrm{O}\right)$ was applied to patients for $10 \mathrm{~min}$. In the asthmatic group, the reversible effect of nCPAP on bronchoconstriction was examined immediately after bronchoconstriction, measured as a $20 \%$ decrease in FEV1, had been induced by methacholine. During this period, the bronchoconstrictor response to methacholine may spontaneously diminish with time. Therefore, the effect of nCPAP must be compared with time control. To cope with this problem, the 18 asthmatic patients were randomly divided into one group of nine patients ( 5 males and 4 females) receiving nCPAP of $6 \mathrm{cmH}_{2} \mathrm{O}$ and another group of nine patients ( 5 males and 4 females) wearing a nasal mask without any pressure or flow (sham pressure) as a time control. Since wearing a mask without flow cannot be considered a true placebo, we considered a cross-over and double-blind study design was not suitable for this study. We also adopted dyspnoea score to examine the effect of nCPAP, we considered a cross-over or double-blind study design was not suitable for this study. During the whole procedure, including measurements of pulmonary function tests, patients remained in a sitting position. Patients with methacholineinduced bronchoconstriction received nebulized salbutamol (5 mg in $1.5 \mathrm{~mL}$ of $0.45 \%$ saline) to reverse the residual bronchospasm after study.

To determine whether the effect of nCPAP on pulmonary function would persist after cessation of nCPAP, 11 of the 18 asthmatic patients were willing to receive another methacholine challenge test. In these 11 subjects, after bronchoconstriction was induced by methacholine (decrease in FEV1 of 20\%), they randomly received nCPAP $(n=6)$ or sham pressure $(n=5)$. Seven patients with RUAO receiving nCPAP were also examined. Spirometry was performed at $30 \mathrm{~s}, 1,2,3,4$ and $5 \mathrm{~min}$ after the removal of nCPAP or sham pressure.

To evaluate whether nCPAP has an influence on the response of airway smooth muscle contraction to bronchodilators, six patients with asthma agreed to be challenged with methacholine to induce a $50 \%$ fall in FEV1 on two separate days (1 week apart). On each occasion, after completion of a methacholine-induced bronchoconstriction, patients immediately received either nCPAP of $6 \mathrm{cmH}_{2} \mathrm{O}$ or sham pressure. Nebulized salbutamol (1 $\mathrm{mg}$ in $1.5 \mathrm{~mL}$ of $0.45 \%$ saline) via a hand nebulizer was given immediately after nCPAP or sham pressure had been applied to the patients. Patients were asked to inhale aerosol via the mouth every other breath and to inhale room air via a nasal mask alternately. All aerosol inhalations were completed within $10 \mathrm{~min}$. The nasal mask was then withdrawn and spirometry was measured at 5, 10, 20 and 30 min thereafter. On the second occasion, patients were crossed over to receive nCPAP or sham pressure, respectively.

The levels of dyspnoea before and during the application of nCPAP or sham pressure were assessed by asking patients to indicate their perceptions of breathlessness on the modified Borg 10 grade scale [21].

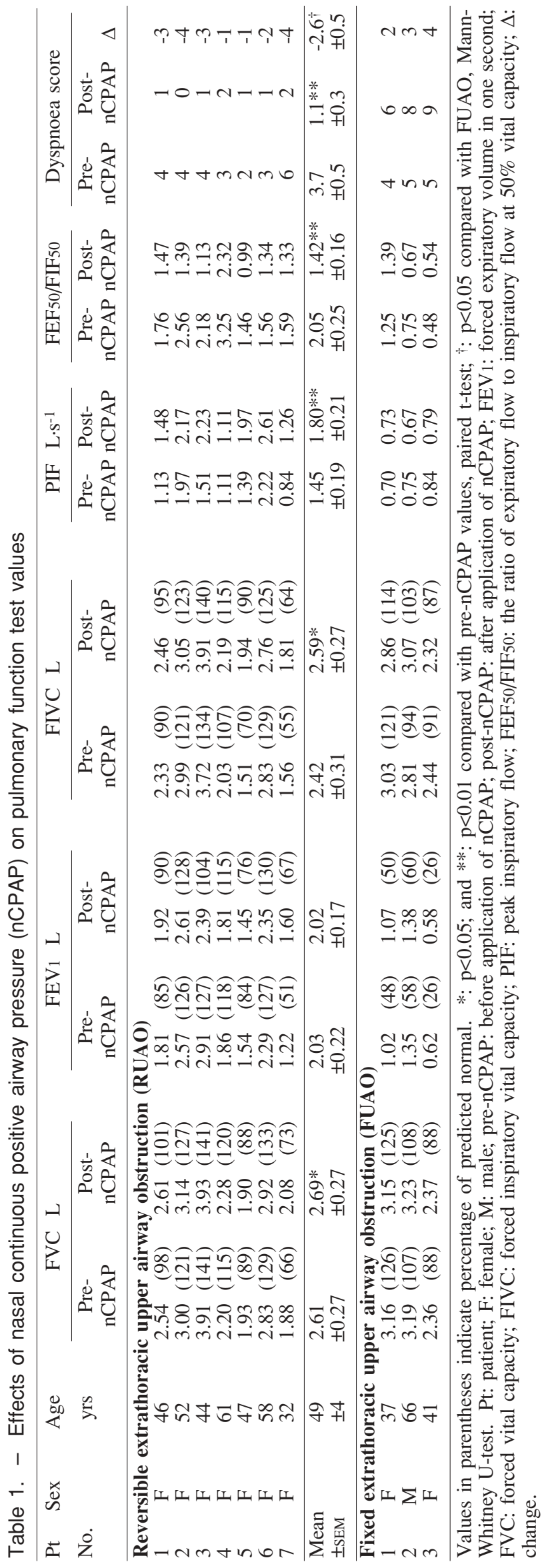




\section{Analysis of results}

Results are presented as mean \pm SEM. Statistical analysis of results was performed by Student's t-test for paired data or one-way analysis of variance (ANOVA) followed by Bonferroni corrected t-test, when multiple comparisons were made. For data with uneven distribution, a Mann-Whitney U-test or a Wilcoxon signed-rank test was used. The relationship between groups was evaluated by linear correlation. A p-value of less than 0.05 was considered significant.

\section{Results}

The characteristics and baseline pulmonary function tests for all patients are presented in tables 1 and 2 .

\section{Effect of nCPAP on upper airway obstruction}

In patients with RUAO $(n=7)$ the application of nCPAP decreased the ratio of FEF50/FIF50 from 2.05 \pm 0.25 to $1.42 \pm 0.16(\mathrm{p}<0.01)($ table 1$)$, and increased PIF and FIVC by $26 \%(\mathrm{p}<0.01)$ and by $9 \%(\mathrm{p}<0.05)$, respectively (table $1)$. In the expiratory phase, there was no significant change in FEV1 $(2 \pm 6 \%)$ or PEFR $(4 \pm 9 \%)$, but a significant improvement in FVC $(4 \pm 1 \%)(\mathrm{p}<0.05)$. However, the changes in airflow rates faded away within $1 \mathrm{~min}$ after removal of nCPAP (data not shown). In contrast, nCPAP had no significant effect on pulmonary function tests in either expiratory or inspiratory phase in the patients with FUAO (table 1). A typical tracing is shown in figure 1. The clinical symptoms of inspiratory stridor and hoarseness were alleviated dramatically after using nCPAP in patients with RUAO, but subjects with FUAO felt more uncomfortable during the application of nCPAP. nCPAP significantly improved the dyspnoea scores in patients with RUAO by $-2.6 \pm 0.5(\mathrm{p}<0.05)$ compared with baseline. The magnitude of change in dyspnoea score was significantly favourable in patients with RUAO than patients with FUAO $(n=3)(3 \pm 0.6)$ (table 1). In both groups, the changes in dyspnoea score returned to baseline within $1 \mathrm{~min}$ after removal of nCPAP.

Table 2. - Baseline data of the patients with lower airway obstruction before nasal continuous positive airway pressure (nCPAP)

\begin{tabular}{|c|c|c|c|}
\hline & \multicolumn{2}{|c|}{ Asthma ${ }^{\dagger}$} & \multirow[t]{2}{*}{ COPD } \\
\hline & Study group & Control group & \\
\hline Age yrs & $29 \pm 3$ & $37 \pm 5$ & $67 \pm 2 * *$ \\
\hline $\operatorname{Sex} \quad M / F$ & $5 / 4$ & $5 / 4$ & $7 / 2$ \\
\hline \multirow{2}{*}{$\begin{array}{l}\mathrm{FVC}^{\#} \mathrm{~L} \\
\quad \% \text { pred }\end{array}$} & $3.09 \pm 0.22$ & $2.95 \pm 0.37$ & $2.34 \pm 0.26$ \\
\hline & $89 \pm 4$ & $86 \pm 6$ & $81 \pm 12$ \\
\hline \multirow{2}{*}{$\mathrm{FEV}^{\# \#}{ }_{\%}^{\mathrm{L}}$} & $1.88 \pm 0.16$ & $1.73 \pm 0.20$ & $1.18 \pm 0.16$ \\
\hline & $64 \pm 5$ & $62 \pm 6$ & $59 \pm 7$ \\
\hline
\end{tabular}

\#: mean士SEM. COPD: chronic obstructive pulmonary disease; $\%$ pred: percentage of predicted normal. For further abbreviations see legend to table $1 .{ }^{\dagger}$ : data of FVC and FEV1 in asthmatic patients indicate those after methacholine challenge. $* *$ : $\mathrm{p}<0.01$ compared with asthma group; analysis of variance (ANOVA) test.
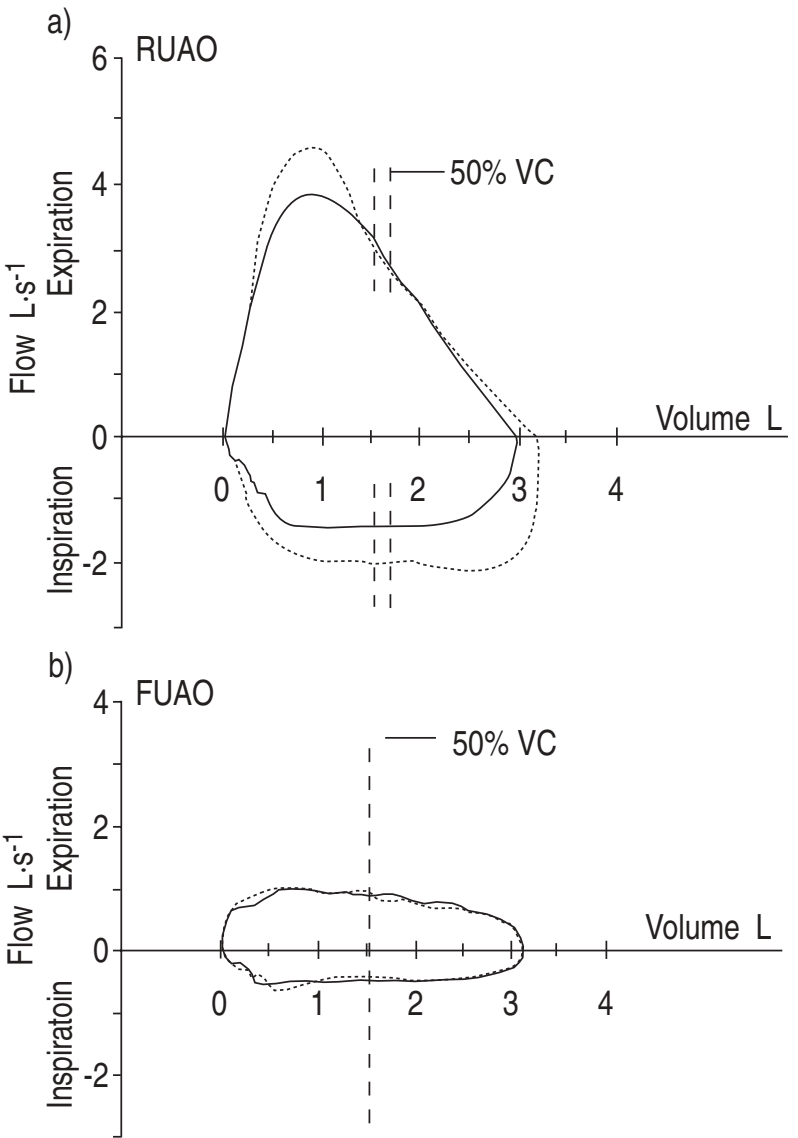

Fig. 1. - The effects of nCPAP on maximum flow-volume curves. a) represents Case No. 2 of RUAO; and b) represents Case No. 1 of FUAO. a) The upper airway obstruction was improved after application of nCPAP (dotted line) compared with before (solid line), whereas (b) the flow-volume curve was unaltered. nCPAP: nasal continuous positive airway pressure; RUAO: reversible upper airway obstruction; FUAO: fixed upper airway obstruction; VC: vital capacity.

\section{Effect of $n C P A P$ on lower airway obstruction}

For patients with bronchial asthma $(\mathrm{n}=9)$, methacholineinduced bronchoconstriction was significantly improved by nCPAP increasing FVC from $3.09 \pm 0.22$ to $3.42 \pm$ $0.28 \mathrm{~L}(\mathrm{p}<0.01), F E V 1$ from $1.88 \pm 0.16$ to $2.16 \pm 0.19 \mathrm{~L}$ $(\mathrm{p}<0.01)$ (fig. 2), and isoFEF25-75\% from $0.86 \pm 0.14$ to $1.28 \pm 0.22 \mathrm{~L} \cdot \mathrm{s}^{-1}(\mathrm{p}<0.01)$ in the expiratory phase (fig. 2 ), as well as FIVC (from $2.93 \pm 0.22$ to $3.27 \pm 0.30 \mathrm{~L}$ ) $(\mathrm{p}<0.05)$ and PIF (from $3.65 \pm 0.48$ to $4.57 \pm 0.47 \mathrm{~L} \cdot \mathrm{s}^{-1}$ ) $(\mathrm{p}<0.05)$ in their inspiratory phase (fig. 2). However, there was no significant effect of sham pressure on the flow rates in either inspiratory or expiratory phase. These effects persisted consistently for at least $5 \mathrm{~min}$ after removal of nCPAP (fig. 3). The percentage change in FEV1 after application of nCPAP was significantly related to response to the following inhalation of bronchodilator $(r=0.82 ; \mathrm{p}<0.0001)(\mathrm{n}=18)$ (fig. 4). nCPAP improved the bronchodilator response to salbutamol $(1 \mathrm{mg})$ in methacholine-induced bronchoconstriction significantly at 5 and $10 \mathrm{~min}$ after inhalation compared to patients receiving sham pressure (fig. 5). In contrast, nCPAP failed to affect pulmonary function in patients with COPD (fig. 2).

Dyspnoea scores for patients with asthma were significantly improved after application of nCPAP $(n=9)$ (by $-3.0 \pm 0.5$, from $4.2 \pm 0.3$ to $1.2 \pm 0.3)(\mathrm{p}<0.01)$ compared 

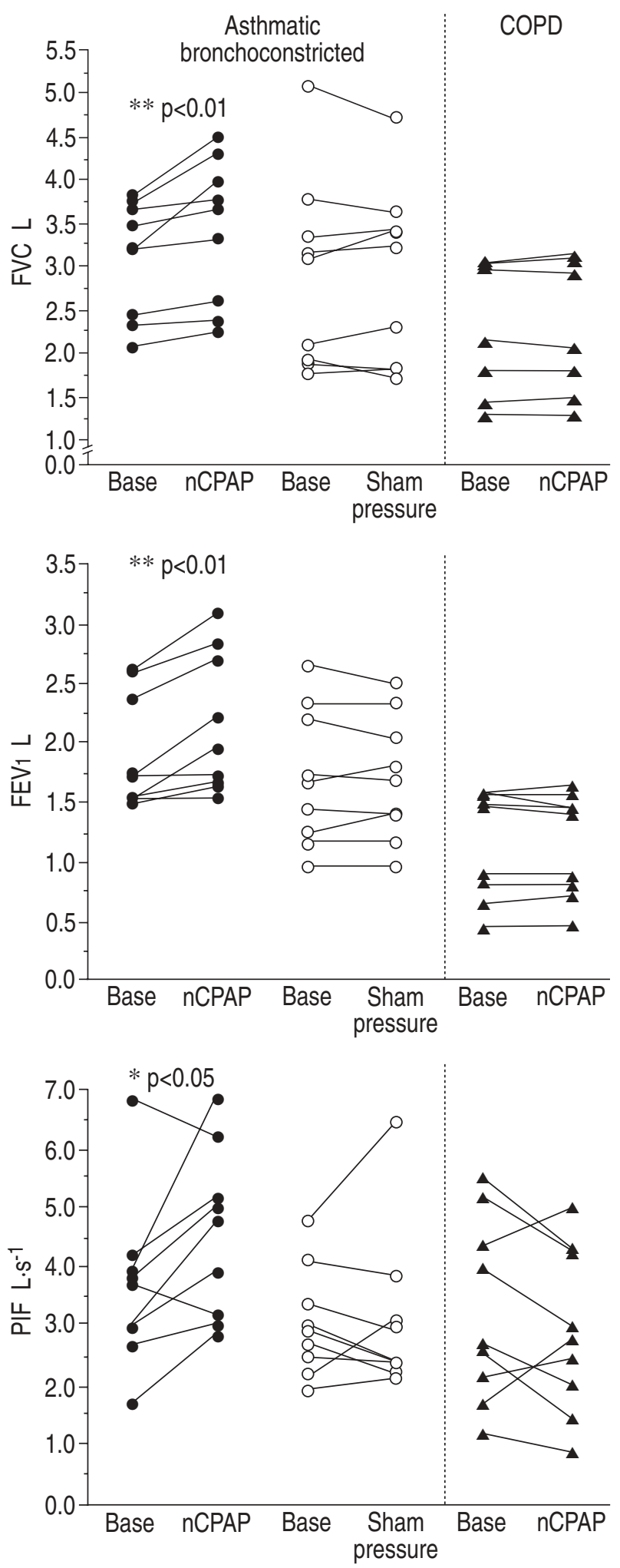

Fig. 2. - The effect of nCPAP $(n=9)$ or sham pressure $(n=9)$ on individual pulmonary function tests in asthmatic patients with methacholine-induced bronchoconstriction; and the effect of nCPAP on patients with COPD $(n=9)$. The significance indicated was compared with the baseline values (Base) before application of nCPAP which expressed the data after methacholine challenge, except in the COPD group. nCPAP: nasal continuous positive airway pressure; COPD: chronic obstructive pulmonary disease; FVC: forced vital capacity; FEV1: forced expiratory volume in one second; PIF: peak inspiratory flow. with those of patients with sham pressure $(n=9)$ (by $-0.1 \pm 0.7$, from $3.7 \pm 0.3$ to $3.6 \pm 0.6$ ). The improvement in dyspnoea scores was also maintained for at least $5 \mathrm{~min}$ after withdrawal of nCPAP. There was no significant change in dyspnoea scores with nCPAP in the COPD group ( $n=9$ ) (by $-1 \pm 0.6$, from $3.1 \pm 0.5$ to $4.1 \pm 0.5$ ). The changes in dyspnoea score in patients with methacholineinduced bronchoconstriction and COPD $(n=18)$ significantly paralleled the improvement in isoFEF25-75\% ( $\mathrm{r}=$ $-0.85 ; \mathrm{p}<0.0001)$, FEV1 $(\mathrm{r}=-0.71 ; \mathrm{p}<0.001)$ and FVC $(\mathrm{r}=$ $-0.64 ; \mathrm{p}<0.01)$, as well as FIVC $(\mathrm{r}=-0.56 ; \mathrm{p}<0.05)$ and PIF $(\mathrm{r}=-0.55 ; \mathrm{p}<0.05)$.

\section{Discussion}

This study demonstrated that nCPAP significantly relieved airway obstruction induced by methacholine and

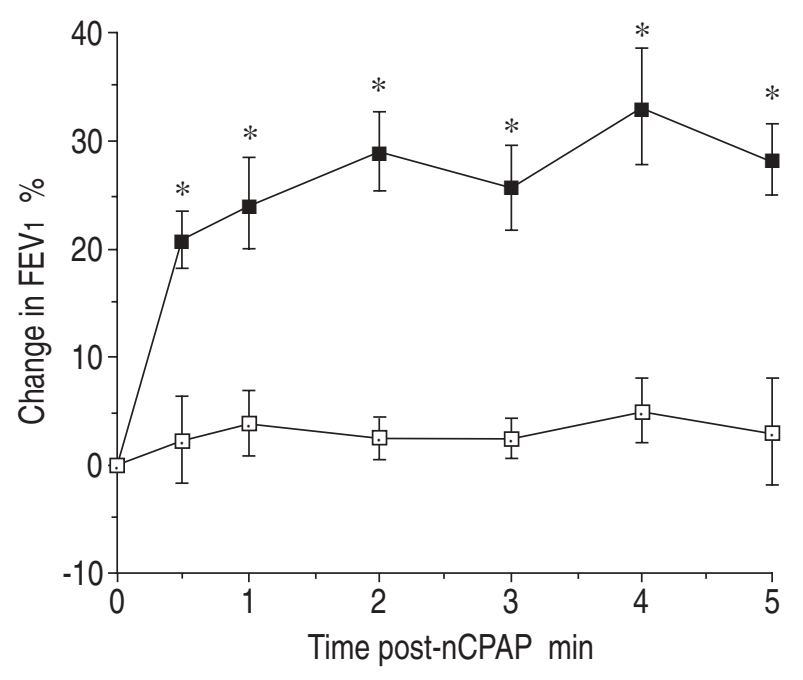

Fig. 3. - The time-course for the changes in FEV1 after abrupt cessation of nCPAP $(n=6)$ or sham pressure $(n=5)$ in asthmatic patients with methacholine-induced bronchoconstriction. Data are presented as mean \pm SEM. *: $\mathrm{p}<0.01$, compared with corresponding sham pressure control. -—: nCPAP; - - - : sham pressure. FEV1: forced expiratory volume in one second; nCPAP: nasal continuous positive airway pressure.

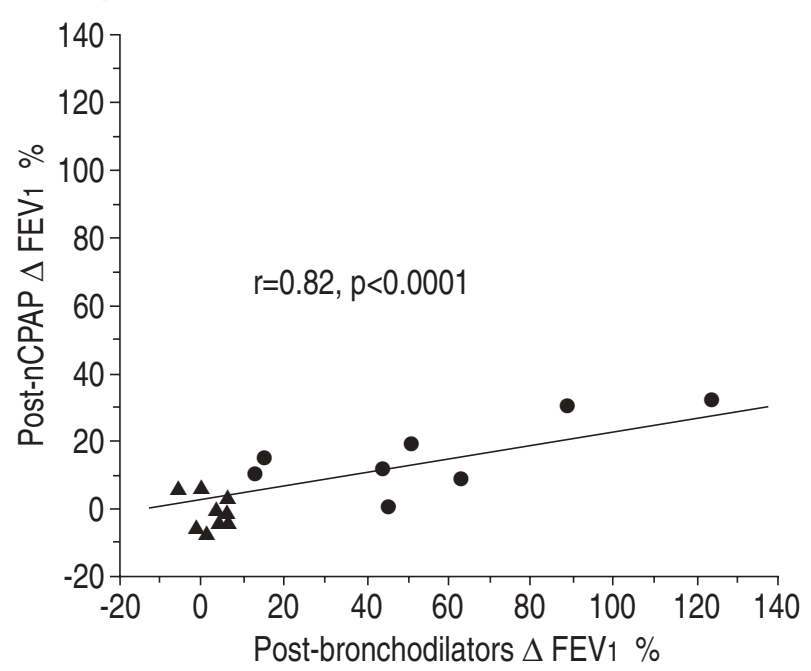

Fig. 4. - The relationship between the change in forced expiratory volume in one second (FEV1) after nCPAP and the response to bronchodilators in patients $(n=18)$ with methacholine-induced bronchoconstriction and COPD. $\bullet$ : asthma; $\Delta$ : COPD. For abbreviations see legend to figure 2 . 


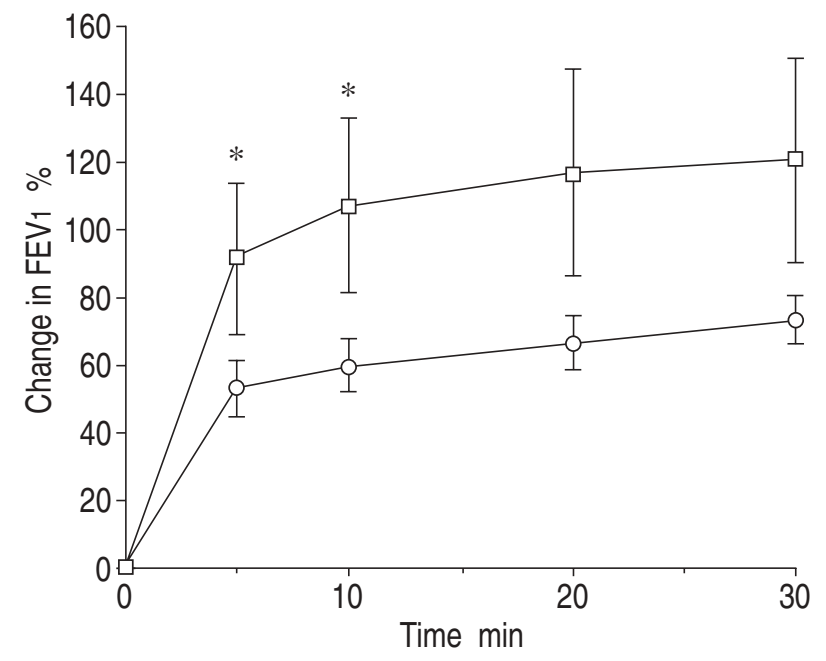

Fig. 5. - The time-course for the changes in FEV1 after inhalation of a low dose of salbutamol $(1 \mathrm{mg})$ with a concomitant use of nCPAP $(n=6)$ or sham pressure $(n=6)$ during the inhalation in patients with methacholine-induced bronchoconstriction. Data are presented as mean \pm SEM. *: $\mathrm{p}<0.05$ compared with the corresponding sham pressure group. $-\square-$ : nCPAP + salbutamol; $-\mathrm{O}-$ : sham pressure + salbutamol. For abbreviations see legend to figure 2 .

variable extrathoracic airway obstruction, but there was no significant improvement in patients with COPD or fixed extrathoracic airway obstruction. The improvement in airflow rate was maintained for at least $5 \mathrm{~min}$ in methacholine-induced airway obstruction, but was more transient in variable extrathoracic airway obstruction. Changes in the subjective dyspnoea score paralleled those in pulmonary function. For patients with reversible lower airway obstruction, an improvement in the expiratory function predominated, whilst there was a predominant improvement in inspiratory function in patients with RUAO. nCPAP also enhanced the effect of bronchodilators on methacholine-induced bronchoconstriction.

\section{Effect of $n C P A P$ on upper airway obstruction}

In patients with RUAO, the upper airway resistance is increased during the inspiratory phase by an increase in negative inspiratory pressure. An increase in the velocity of air passing through the site of narrowing leads to a further reduction in intraluminal pressure (Bernoulli effect) $[19,22]$. Such a subatmospheric intraluminal pressure causes pharyngeal collapse at a given site of narrowing during inspiration. During the expiratory phase, the intraluminal pressure becomes positive and the variable extrathoracic obstruction improves. Therefore, the introduction of a CPAP in our patients with RUAO may have alleviated the effect of a subatmospheric pressure on the extrathoracic airway obstruction by an increase in the intraluminal pressure.

In the present study, a persistent high flow generated by the nCPAP interfered with the measurements of pulmonary function. Thus, we did not measure airway resistance during the application of nCPAP. However, the stridor and dyspnoea scores promptly and significantly improved after application of nCPAP in patients with RUAO. Immediately after removal of nCPAP, the improvement in the airflow rates was still present but it faded away quickly within $1 \mathrm{~min}$, indicating that nCPAP was effective in relieving RUAO. Subjective dyspnoea scores paralleled the changes in airflow rate after removal of nCPAP.

In patients with FUAO, the cross-sectional area did not change in response to transmural pressure difference. Therefore, the imposed nCPAP failed to improve the airflow rate in patients with FUAO. The introduction of a positive pressure in the upper airways may stimulate pharyngeal mechanoreceptors to stiffen the upper airway [23]. It is possible that this neural reflex may contribute to the efficacy of nCPAP in RUAO, and maintain a transient effect after removal of the pressure by stiffening the upper airways and subsequently decreasing the vulnerability to intraluminal pressure change. However, there seems to be no significant effect of this neural reflex in patients with FUAO.

\section{Effect of $n C P A P$ on bronchoconstriction in asthma and stable COPD}

The efficacy of nCPAP was also shown in alleviating the methacholine-induced airway obstruction in patients with bronchial asthma. It is possible that nCPAP merely offers a pneumatic splinting effect, which may oppose smooth muscle contraction and, therefore, decrease airway resistance. However, such a counteracting effect on airway smooth muscle contraction may quickly fade away after removal of the pressure. In the present study, the improvement in FEV1 was maintained for at least $5 \mathrm{~min}$ after removal of nCPAP. The mechanism for this persistent effect was not clarified in the present study.

We recently demonstrated that application of nCPAP significantly decreased the reactivity to methacholine challenge in patients with bronchial asthma [24]. The effect of nCPAP influenced not only the maximal response but also the slope of dose-response curves, suggesting that nCPAP may alter the intrinsic property of smooth muscle in response to stimuli. In patients with bronchial asthma, airway wall oedema and inflammation are responsible for the development of airway hyperresponsiveness, an exaggerated smooth muscle contractile response to stimuli including methacholine. It was reported that a decrease in airway mucosal oedema caused by vasoconstriction may attenuate the responsiveness to methacholine $[25,26]$. Therefore, in the present study, nCPAP may exert a pressurizing effect on the airway mucosa, decrease airway oedema, and thereby attenuate the exaggerated responsiveness to methacholine in asthmatic airways. In addition, a concomitant use of nCPAP during inhalation of a low dose of salbutamol significantly enhanced the bronchodilator effect on methacholineinduced bronchoconstriction in asthmatic patients, indicating that nCPAP may improve the airway smooth muscle responsiveness. The effect persisted for at least $10 \mathrm{~min}$ after the withdrawal of nCPAP. This was further supported by the highly significant relationship between the change in FEV1 after application of nCPAP and the response to following inhalation of salbutamol in relieving methacholine-induced bronchoconstriction.

Since methacholine-induced bronchoconstriction may regress spontaneously or by deep inspiration [27], it is possible that the nCPAP-induced reversibility may be due to a spontaneous regression or the bronchodilator 
effect of deep breathing. However, the negative response to sham pressure in the present study argued against this possibility.

Methacholine might cause air-trapping with a concomitant increase in residual volume (RV) and a decrease in FEV1 [28]. The increase in RV resulting from dynamic airway collapse by methacholine may increase the load on inspiratory muscle [29], and reduce the extent of muscle force needed to overcome the airway resistance of obstruction. The decrease in airway resistance by nCPAP in the present study might, therefore, be mediated via a reduction in the load on the inspiratory muscle [11], and subsequent improvement in the inspiratory phase pulmonary function as well as the expiratory effort (muscular pressure) which the maximal expiratory flow is dependent on [30]. This response to nCPAP may, to some extent, contribute to the improvement in pulmonary function presented in this study. This effect has been well demonstrated in COPD patients with a decrease in breathing work by overcoming the intrinsic positive endexpiratory pressure (PEEPi) $[9,31]$. In the present study, however, nCPAP was applied to our COPD patients, but failed to improve their airway resistance, indicating that a reduction in the respiratory muscle load by overcoming the PEEPi did not necessarily improve airflow rates. This result was consistent with a recent report by PETROF et al. [31]. In addition, the mechanical splinting effect of nCPAP was not expected to persist after removal of nCPAP. However, the small number of patients studied does not allow complete exclusion of the clinical efficacy of nCPAP in COPD patients.

Pulmonary function tests carried out immediately after abrupt cessation of nCPAP were unable to demonstrate a true effect of nCPAP on ventilatory function. The present study provided no information about the changes in airway resistance whilst receiving nCPAP. However, changes in dyspnoea scores were assessed to represent overall response to nCPAP and showed a high correlation with the improvement in either expiratory or inspiratory ventilatory functions. Previous reports have also demonstrated that the sensation of breathlessness increased as FEV1 decreased [21], and that the change of FEV1 after use of bronchodilators was highly correlated with the change in dyspnoea scores [32]. Therefore, the improvement in dyspnoea scores whilst receiving nCPAP may, to some extent, suggest that an improvement in airflow rates occurred only during nCPAP.

Although our results showed a negative effect of nCPAP on airway resistance in COPD patients, it cannot preclude the clinical application of CPAP in these patients. In a recent study, a significant improvement in gas exchange was demonstrated by administration of positive-pressure ventilation via face mask to patients with acute exacerbation of COPD [33]. In addition, improvement in ventilatory function has also recently been reported in COPD patients acutely treated with noninvasive nasal mask with bi-level positive airway pressure support (BiPAP) or intermittent positive pressure ventilation [33-35]. Patients with COPD may benefit more from BiPAP than CPAP, since active expiration during the positive expiratory pressures of nCPAP decreases the compliance of the airways. Although most of this effect can be attributed to the decrease in breathing work by overcoming the PEEPi, CPAP might attenuate airway responsiveness to stimuli and enhance bronchodilator response during acute exacerbations, a similar effect of nCPAP to that demonstrated in asthmatics in the present study.

In conclusion, the effect of nasal continuous positive airway pressure on airway resistance depends on the nature of the airway obstruction. Airway obstruction caused by structural changes either in the upper or lower airways may not benefit from the application of nasal continuous positive airway pressure in improving airflow rates. Nasal continuous positive airway pressure is efficient in alleviating reversible airway obstruction by a change in either intraluminal pressure in patients with reversible upper airway obstruction or in airway responsiveness in asthmatic patients. Our results did not indicate an immediate applicability of nasal continuous positive airway pressure in the treatment of obstructive airway disease, but provided an insight into different aspects of the effect of its effects in clinical use.

\section{References}

1. Remmers JE, de Groot WJ, Sauerland EK, Anch AM. Pathogenesis of upper airway occlusion during sleep. $J$ Appl Physiol: Respirat Environ Exercise Physiol 1978; 44: 931-938.

2. Sullivan CE, Issa FG, Berthon-Jones M. Reversal of obstructive sleep apnoea by continuous positive airway pressure applied through the nares. Lancet 1981; i: 862-865.

3. Strohl KP, Redline S. Nasal CPAP therapy, upper airway muscle activation and obstructive sleep apnea. Am Rev Respir Dis 1986; 134: 555-558.

4. Rapoport DM, Sorkin B, Garay SM, Goldring RM. Reversal of the "Pickwickian syndrome" by long-term use of nocturnal nasal airway pressure. N Engl J Med 1982; 307: 931-933.

5. Zitsch III RP. Continuous positive airway pressure use in bilateral vocal cord paralysis. Arch Otolaryngol Head Neck Surg 1992; 118: 875-876.

6. Ferguson GT, Benoist J. Nasal continuous positive airway pressure in the treatment of tracheobronchomalacia. Am Rev Respir Dis 1993; 147: 457-461.

7. Remmers JE, Sterling JA, Thorannsson B, Kuna ST. Nasal airway positive pressure in patients with occlusive sleep apnea. Am Rev Respir Dis 1984; 130: 1152-1155.

8. Miller MJ, Difiore JM, Strohl KP, Martin RJ. Effects of NCPAP on supraglottic and total pulmonary resistance in preterm infants. J Appl Physiol 1990; 68: 141-146.

9. Smith TC, Marini JJ. Impact of PEEP on lung mechanics and work of breathing in severe airflow obstruction. J Appl Physiol 1988; 65: 1488-1499.

10. Miro AM, Shivaram U, Hertig I. Continuous positive airway pressure in COPD patients in acute hypercapnic respiratory failure. Chest 1993; 103: 266-268.

11. Martin JG, Shore S, Engel LA. Effect of continuous positive airway pressure on respiratory mechanics and pattern of breathing in induced asthma. Am Rev Respir Dis 1982; 126: 812-817.

12. Marini JJ. Should PEEP be used in airflow obstruction? Am Rev Respir Dis 1989; 140: 1-3.

13. Smith PG, El-Khatib MF, Carlo WA. PEEP does not improve pulmonary mechanics in infants with bronchiolitis. Am Rev Respir Dis 1993; 147: 1295-1298.

14. Christensen HR, Simonsen K, Lange P, et al. PEEPmasks in patients with severe obstructive pulmonary 
disease: a negative report. Eur Respir J 1990; 3: 267272.

15. Wilson BA, Jackson PJ, Evans J. Effects of positive end-expiratory breathing on exercise-induced asthma. Int J Sports Med 1981; 2: 27-30.

16. Barnes PJ. New concepts in the pathogenesis of bronchial hyperresponsiveness and asthma. J Allergy Clin Immunol 1989; 83: 1013-1026.

17. American Thoracic Society. Standards for the diagnosis and care of patients with chronic obstructive pulmonary disease (COPD) and asthma. Am Rev Respir Dis 1987; 136: 225-244.

18. Acres JC, Kryger MH. Clinical significance of pulmonary function tests. Chest 1981; 80: 207-211.

19. Rotman HH, Liss HP, Weg JG. Diagnosis of upper airway obstruction by pulmonary function testing. Chest 1975; 68: 796-799.

20. American Thoracic Society. Standardization of spirometry: 1987 update. Am Rev Respir Dis 1987; 136: 12851293.

21. Burdon JGW, Juniper EF, Killian KJ, Hargreave FE, Campbell EJM. The perception of breathlessness in asthma. Am Rev Respir Dis 1982; 126: 825-828.

22. Templer JW, von Doersten PG, Quigley PR, Scott GC, Davis WE. Laryngeal airway resistance: the relationships of airflow, pressure and aperture. Arch Otolaryngeal Head Neck Surg 1991; 117: 867-870.

23. Hoffstein V, Slutsky AS. Central sleep apnea reversed by continuous positive airway pressure. Am Rev Respir Dis 1987; 135: 1210-1212.

24. Lin HC, Wang CH, Yang CT, et al. Effect of nasal continuous positive airway pressure on methacholine-induced bronchoconstriction. Respir Med 1995; 89: 121-128.

25. Cabanes L, Wener SN, Martran R, et al. Bronchial hyperresponsiveness to methacholine in patients with impaired left ventricular function. N Engl J Med 1989; 320: $1317-1322$.
26. Cabanes L, Costes F, Weber S, et al. Improvement in exercise performance by inhalation of methoxamine in patients with impaired left ventricular function. $N$ Engl J Med 1992; 326: 1661-1665.

27. Orehek J, Nicoli MM, Delpierre S, Beaupre A. Influence of the previous deep inspiration on the spirometric measurement of provoked bronchoconstriction in asthma. Am Rev Respir Dis 1981; 123: 269-272.

28. Wassermann K, Pothoff G, Bahra J, Hilger HH. Reversible volume changes of trapped gas in nonspecific bronchoprovocation tests. Chest 1992; 101: 970-975.

29. Martin JG, Shore SA, Engel LA. Mechanical load and inspiratory muscle action during induced asthma. Am Rev Respir Dis 1983; 128: 455-460.

30. Hyatt RE, Schilder DP, Fry DL. Relationship between maximum expiratory flow and degree of lung inflation. J Appl Physiol 1958; 13: 331-336.

31. Petrof BJ, Legare M, Goldberg P, Milic-Emili J, Gottfried SB. Continuous positive airway pressure and dyspnea during weaning from mechanical ventilation in severe chronic obstructive pulmonary disease. Am Rev Respir Dis 1990; 141: 281-289.

32. Janson C, Herala M. Dyspnea in acute asthma: relationship with other clinical and physiologic variables. Ann Allergy 1993; 70: 400-404.

33. Brochard L, Isabey D, Piquet J, et al. Reversal of acute exacerbations of chronic obstructive lung disease by inspiratory assistance with a face mask. N Engl J Med 1990; 323: $1523-1530$.

34. Meduri GA, Abou-Shala N, Fox RC, Jones CB, Leeper KV, Wunderink RG. Noninvasive face mask mechanical ventilation in patients with acute hypercapnic respiratory failure. Chest 1991; 100: 445-454.

35. Confalonieri M, Aiolfi S, Gandola L, Scartabellati A, Della Porta R, Parigi P. Severe exacerbations of chronic obstructive pulmonary disease treated with BiPAP® by nasal mask. Respiration 1994; 61: 310-316. 